\section{Desigualdade, pobreza e obesidade}

\author{
Inequality, poverty and obesity
}

Vanessa Alves Ferreira ${ }^{1}$

Aline Elizabeth Silva ${ }^{2}$

Chrystiellen AyanaAparecida Rodrigues ${ }^{2}$

Nádia Lúcia Almeida N unes ${ }^{2}$

Tássia Cassimiro Vigato ${ }^{2}$

Rosana M agalhães ${ }^{3}$

${ }^{1}$ Departamento deN utrição, FaculdadedeCiências Biológicaseda Saúde, UniversidadeFederal dos Vales do Jequitinhonhae Mucuri. Rua da Glória 187/ sala 28, Centro. 39100-000 Diamantina M G.

vanessa.nutr@ig.com.br ${ }^{2}$ Graduação em Nutrição, UniversidadeFederal dos Valesdo Jequitinhonhae Mucuri.

${ }^{3}$ Departamento deCiências Sociais, Escola Nacional de Saúde Pública Sérgio Arouca, Fundação Oswaldo Cruz.
Abstract National studies have been demonstrating the positive relationship among inequality, poverty and obesity revealing thesingularities and complexity of the nutritional transition in Brazil. In this direction, the women constitute a vulnerable group to the dynamics of the obesity in the poverty context. Such fact imposes the theoretical deepening and the accomplishment of researches that make possiblea larger approach with the phenomenon in subject. In this perspective, the study analyzed the daily life of poor and obese women, users of basic units of health of the city of Diamantina, Vale do Jequitinhonha, M inas Gerais State. The results revealed the complex relationship between feminine obesity and poverty. The cultural and material aspects of life, as well as the different feeding and body conceptions that demonstrated to befundamental elements for the analysis of the multiple faces of the obesity among the investigated group. Facing these results it is appropriate to encourage public policies that promote equity widening the access of those groups to the main resources for the prevention and combat of obesity.

Key words Poverty, O besity, N utritional status, Food habits
Resumo Estudos nacionais têm demonstrado a relação positiva entre desi gual dade, pobreza eobesidade, revelando a singularidadeea complexidade da transição nutricional no Brasil. N esta direção, as mulheres constituem um grupo vulnerável à dinâmica da obesidade no contexto da pobreza. Tal fato impõe o aprofundamento teórico e a realização de pesquisas que possibilitem uma maior aproximação com o fenômeno em questão. N esta perspectiva, o estudo analisou o cotidiano de vida de mulheres pobres e obesas, usuárias de unidades básicas de saúde da cidade de Diamantina, Vale do Jequitinhonha (M G). Os resultados revelaram a imbricada relação entre obesidade feminina e pobreza. O s aspectos culturais e materiais de vida, assim como as diferentes concepções de alimentação e de corpo, demonstraram ser elementos fundamentais para a análise das múltiplas faces da obesidade entre o grupo investigado. Frente a esses resultados, torna-se oportuno fomentar políticas públicas que promovam maior equidade, ampliando 0 acesso desses grupos aos principais recursos para a prevenção e o combate à obesidade.

Palavras-chave Pobreza, 0 besidade, Estado nutricional, $\mathrm{H}$ ábitos alimentares 
Introdução

0 incremento da obesidade em populações que vivem em situação de pobreza tem sido destacado pela literatura e por instituições internacionais ${ }^{1,2}$. É notável a ascensão da obesidade em países em desenvolvimento, tais como as sociedades latino-americanas². N o Brasil, os dados provenientes de inquéritos nacionais realizados no período de 1974 a 2003 revelaram a evolução da obesidade global na população adulta brasileira e seu impacto nos segmentos menos favorecidos $^{3}$. N este contexto, observa-se a vulnerabilidade do grupo feminino à dinâmica da obesidade na pobreza ${ }^{3,4}$. De acordo com a Pesquisa de Orçamentos Familiares real izada pel o I nstituto Brasileiro de Geografia eEstatística, "no período mais recente, o problema do excesso de peso em muIheres tende a se deslocar para a região nordeste e, de modo geral, para as classes de menor ren$\mathrm{da}^{\prime \prime}$. Contrariamente, entre o grupo masculino, a evolução do excesso de peso tem apresentado comportamento mais contínuo em todas as re giões brasileiras e classes sociais. O bserva-se que a maior frequência do excesso de peso ocorre nos estratos de maior rendimento, especialmente naqueles indivíduos que residem nas Regiões Sul, Sudeste e Centro-Oeste do país ${ }^{3}$.

A tendência da obesidade no contexto da pobreza no Brasil coloca o agravo como tema prioritário para o campo da saúde pública na atualidade ${ }^{5,6}$. A preocupação com as repercussões da obesidade nos grupos menos favorecidos impõe o aprofundamento teórico sobre sua dinâmica e o delineamento de políticas públicas mais eficazes para a preven ção eo controle da enfermidade nesses segmentos. Nesta direção, este trabalho busca contribuir para o melhor entendimento da dinâmica da obesidade entre mulheres brasileiras, especialmente as que vivem em condições de pobreza. Dessa forma, este estudo procurou combinar aspectos epidemiológicos ligados ao quadro de crescimento da obesidade, utilizando dados provenientes da última pesquisa de âmbito nacional ${ }^{3}$, com informações de natureza sociocultural e simbólica7. Para isso, o objetivo foi analisar as práticas alimentares e o estilo de vida de mulheres obesas usuárias de unidades básicas desaúde da cidade deDiamantina, região do Vale do Jequitinhonha (M G). 0 estudo teve a perspectiva de combinar diferentes possibilidades analíticas visando, porém, dar ressonância aos aspectos socioculturais e simbólicos ${ }^{7}$. Dessa forma, privilegiou-se o discurso das mulheres a respeito desuas práticas alimentares cotidianas, seus corpos, suas condições de vida, trabal ho e lazer, por intermédio da pesquisa qualitativa.

A cidade de Diamantina e o Vale do Jequitinhonha (MG)

A cidade de Diamantina localiza-se na região noroeste do Estado de M inas Gerais, a 297 quilômetros da capital Belo Horizonte. De acordo com os dados provenientes do Instituto Brasileiro de Geografia e Estatística ${ }^{8}$ para 0 ano de 2007, o município possui uma população adstrita de cerca de 88 mil habitantes. A cidade caracterizouse como a maior produtora de pedras preciosas e de ouro do século XVIII e pertence ao Circuito do Diamante e da Estrada Real ${ }^{9}$. Atualmente, a exuberância histórica, artística e cultural da cidadeé preservada e revalorizada por intermédio do título de Patrimônio Cultural da Humanidade, concedido pela Unesco no ano de 19979. A cidade de Diamantina se insere ainda na região do Vale do J equitinhonha, considerada uma das áreas de maior desigualdade e exclusão social do país. Dados do Instituto dePesquisa Econômica eAplicada (IPEA) para 0 ano de $2007^{10}$ confirmam a espacialização da pobreza na região. A existência de indivíduos vivendo em condições de pobreza eindigência atingiu o índicede $30 \%$, considerado um dos mais elevados do país, semelhante apenas às regiões do norte e nordeste ${ }^{10}$.

Particularmente no quediz respeito aos indicadores nutricionais, os dados obtidos do Sistema de Vigilância Alimentar e Nutricional (SISVAN ) da Secretaria Municipal de Saúde de Diamantina revelam prevalências bastante expressivas de obesidade na população. Entre adultos, a enfermidade passou de 7,7\% para $16,7 \%$, no período de 2002 a $2007^{11}$. Esses dados corroboram com as prevalências atuais do excesso de peso no país. De acordo com a pesquisa do IBGE, a obesidadefoi prevalenteem $11 \%$ da população adulta brasilei ra ${ }^{3}$. Tal fenômeno reflete a dinâmica singular assumida pela transição nutricional no Brasil com a conformação de um quadro nutricional complexo e ambivalente ${ }^{12}$, no qual a problemática da obesidade no contexto da pobreza é apenas uma das suas múltiplas faces.

\section{M etodologia}

Este trabalho apresenta parte dos resultados da pesquisa intitulada "O besidade-Jequi", realizada com mulheres obesas submetidas a condiç̧ões de 
vulnerabilidade social e moradoras da cidade de Diamantina (M G). 0 levantamento das referências bibliográficas foi feito a partir das principais bases digitais de dados, tais como M EDLINE e Lilacs, assim como em bibliotecas especializadas, compreendendo as do Instituto de Pesquisa Econômica e Aplicada (IPEA/RJ), Fundação Getúlio Vargas (FGV/RJ), Fundação João Pinheiro (FJP/ M G) e Escola Nacional de Saúde Pública Sérgio Arouca (ENSP-FIOCRUZ/RJ).

0 estudo buscou uma aproximação com 0 vocabulário sobre a alimentação, o corpo, a vida, o trabal ho, o lazer ea obesidade das mulheres do Vale através do instrumental qualitativo. A pesquisa qualitativa assume como tarefa central 0 entendimento da realidade humana vivida socialmente, na qual são priorizados um amplo universo de valores, percepções, hábitos e atitudes dos sujeitos ${ }^{13}$.

0 trabalho decampo totalizou dezenoveentrevistas. Os critérios para a seleção do grupo incluíram o diagnóstico da obesidade a partir do parâmetro do índice de massa corporal (IMC) ${ }^{14} \mathrm{e} \mathrm{a}$ caracterização da condição de vulnerabilidade social a partir do levantamento de informações sobre condições de vida e pobreza. N esteúltimo, fizemos uso de uma cesta de indicadores, tal como propõe a literatura25,16. Esta incluiu dados sobre renda, nível educacional, situação do domicílio, estrutura familiar, acesso a bens e serviços, condições de trabalho elazer, entre outras informações.

As mulheres foram convidadas a participar da pesquisa nas unidades básicas de saúde da zona urbana da cidade. As entrevistas eram agendadas e realizadas no domicílio por uma equipe de pesquisadoras treinadas. 0 instrumento para a coleta de dados seguiu um roteiro previamente estabelecido e validado, compreendendo quatro eixos investigativos. 0 primeiro constou de informações acerca da rotina alimentar das entre vistadas, incluindo a aquisição dos gêneros, preparo, consumo, preferências e aversões alimentares. No segundo eixo, foram obtidos dados sobre a rotina diária de atividades laborais e de lazer: meios delocomoção, tipo de atividadeocupacional, realização de atividade esportiva de lazer e horas assistindo tel evisão. 0 terceiro eixo investigativo resgatou informações sobre a trajetória de vida das mulheres. Por último, foram obtidos dados acerca das percepções das mulheres acerca do seu corpo, alimentação econdições de vida e trabalho. Destacamos que foram cumpridos os princípios éticos contidos na Declaração de Helsinki da World M edical Association. $\mathrm{N}$ a etapa da análise dos dados, as entrevistas fo- ram transcritas na íntegra e posteriormente realizou-seuma leitura flutuante detodo o material obtido. Foram sinalizadas as principais idéias ligadas à fundamentação teórica e feita a listagem das entrevistas ${ }^{13}$.

\section{Resultados ediscussão}

Das dezenove mulheres entrevistadas, oito apresentaram obesidade classel, cinco obesidade, classe II e seis obesidade, classe III, com riscos de comorbidademoderado, gravee gravíssimo, respectivamente, de acordo com a classificação da Organização Mundial de Saúde (OMS) ${ }^{14}$. A média do índice de massa corporal (IMC) encontrada foi de $35,34 \mathrm{~kg} / \mathrm{m}^{2}$. No que diz respeito à faixa etária de nosso universo de pesquisa, as mulheres apresentaram idades que variaram de 19 a 58 anos. $\mathrm{Na}$ análise dos indicadores combinados, queteve por objetivo discriminar mulheres submetidas a condições de vulnerabilidade social, observamos que, no que se refere à cor, as mulheres entrevistadas eram em sua maioria pretas ou pardas. Esta característica estáintimamente relacionada à pobreza no Brasil $^{17}$.

A baixa escolaridade também é uma característica dos pobres no país ${ }^{17}$. Neste particular, as mulheres do Vale apresentaram baixo nível educacional: fundamental incompleto. Esteperfil relaciona-se também a menores oportunidades de conquistar postos de trabalho de maior qualificação e melhor condição salarial. N este sentido, as mulheres se encontravam inseridas em postos de trabalho de menor prestígio, exercendo atividades de diaristas, domésticas, babás, dentre outras. De acordo com a pesquisa realizada pela Fundação João Pinheiro no ano de 2006, a maior participação no mercado de trabalho das muIheres no Estado de M inas Gerais era nas ocupações das áreas de serviços (57,9\%), serviços domésticos $(17,4 \%)$ e do comércio $(13,5 \%)^{18}$.

A vulnerabilidade à pobreza é agravada pela falta de uma rede de proteção social. As mulheres não apresentaram vínculos trabalhistas, exercendo suas atividades sem carteira assinada. Ainda de acordo com a pesquisa realizada pela Fundação João Pinheiro's, a informalidade foi maior entre as mulheres no ano de 2006 quando comparada com os homens. A população ocupada com carteira de trabalho assinada foi duas vezes maior no grupo masculino do que no feminino no período analisado. A esse respeito, de acordo com o Instituto de Pesquisa Econômica e Aplicada ${ }^{19}$, as muIheres e os negros são os grupos que apresentam 
os maiores índices de desemprego atualmente no país. Além disso, a participação em programas sociais foi rara no grupo: apenas duas informantes recebiam auxílios provenientes do programa federal Bolsa Família e do programa estadual Leite pela $V$ ida. Os gastos com a alimentação foram baixos, em torno de $R \$ 200,00$ a $R \$ 300,00$ reais mensais: "na base de uns 300 que a gente gasta mais ou menos", "uns duzentos e poucos". A desqualificação das ocupações exercidas por essas mulheres se reflete em baixos rendimentos: a média salarial observada no grupo foi de dois saláriosmínimosmensais. A esserespeito, Sarlio-Lähteenkorva e Lahelma ${ }^{20}$ verificaram a relação positiva entreobesidadefeminina, desemprego ebaixos rendimentos em estudos com mulheres na Finlândia. Neste trabalho, os autores concluíram que as mulheres obesas enfrentam múltiplas desvantagens sociais e econômicas.

O cotidiano de vida das mulheres revel ou ser difícil, sendo a condição social, o desemprego ea doença as questões que mais preocupavam o grupo: "procuro emprego e não acho", "minha saúde está ruim", "o ruim é que eu não posso comprar as coisas que eu quero". No que se refere à infraestrutura, verificamos que todos os domicílios possuíam equipamento de água e esgoto; contudo, existia problemas recorrentes de "falta" de água no bairro: "Numa semana, três dias falta água", "falta água demais!". A coleta de lixo local também se mostrou deficiente: "aqui não tem, eu levo e coloco lá em baixo", "eu queimo o lixo", "eles não pegam na porta", "é bem desorganizada!". A assistência à saúde, de acordo com o grupo, é limitada e obtida em postos de saúde, nas unidades da Estratégia de Saúde da Família, no Programa Agentes Comunitários de Saúde, na policlínica eno hospital municipal: "a gente procura, mas não acha”, "o mais procurado é o plantão, só que está muito difícil".

As famílias eram do tipo mononucleares ${ }^{21} \mathrm{e}$ o número de pessoas residindo no domicílio foi em média de cinco pessoas. A chefia do lar na maior parte dos domicílios ficava a cargo do marido. No entanto, cinco informantes foram classificadas como responsáveis pelo domicílio. Particularmente ao que diz respeito à chefia feminina, os dados recentes da pesquisa do IPEA ${ }^{19}$ revelam que esta é uma tendência crescente no país equeestá relacionada com contextos de precarização da vida e do trabal ho feminino sendo, portanto, considerado um importanteindicador de desigualdade de gênero. Quanto ao nível de instrução dos chefes do domicílio, ele foi baixo; em média, o ensino fundamental incompleto, fato que se correlaciona com o estado de pauperização das famílias urbanas no país ${ }^{21}$.

A rotina de alimentação das mulheres pobres e obesas do Vale do Jequitinhonha foi analisada dentro da perspectiva qualitativa, objetivando colher informações acerca dos critérios para a seleção dos alimentos. N este sentido, verificouse que a aquisição e o preparo dos gêneros eram atividades realizadas pelas próprias mulheres. Eram elas que selecionavam, gerenciavam e preparavam a alimentação da família: "eu escoIho ao meu agrado e ao agrado da família", "eu mesma que tenho que sair pra fazer as compras". Segundo Woortmann ${ }^{22}$, o modelo brasileiro de organização da divisão do trabalho no núcleo familiar atribui às mulheres a prestação de serviços que compreen de os afazeres domésticos e 0 controle da alimentação da família.

A compra dos alimentos era feita em supermercados e em pequenos armazéns localizados em bairros de maior popularidade e que apresentavam uma menor cobertura de infraestrutura elazer, tais como o Rio Grandee a Palha. De acordo com o grupo, a preferência em comprar nesses locais envolvia o fato de ser mais barato, além da facilidade do crédito oferecido: "porque eu compro lá no cheque desde quando abriu", " porque lá é mais barato", "sai mais em conta", "porqueàs vezes a gente não tem dinheiro e pode comprar pra pagar no outro mês". 0 pagamento das compras dos alimentos é, portanto, em certas circunstâncias, realizado no sistema decré dito. A esse respeito, a pesquisa realizada no ano de 2007 pela Federação de Comércio do Rio de Janeiro ${ }^{23}$ revelou queo endividamento écrescente entre as classes menos favorecidas economicamente. De acordo com a pesquisa, as diversas modal idades de financiamento oferecidas a esses segmentos têm contribuído para o acúmulo de débitos no grupo. Os dados revelam que 16\% das pessoas que compõem a classe $C$ e $15 \%$ dos indivíduos categorizados nas classes D e E estão com dívidas no mercado de crédito.

Dentro dos critérios para avaliar o consumo alimentar do grupo, constatou-se a estreita relação existenteentrealimentação e condições socioeconômicas. 0 critério de seleção dos alimentos pelas mulheres do Vale era, na maioria das vezes, pautado pelo valor monetário dos gêneros. 0 preço dos itens definia, na maior parte das situações, a seleção dos alimentos pelo grupo: "eu compro pelo preço". Esta relação entre a condição social e a seleção de alimentos no cotidiano de vida de mulheres obesas tem sido observada em estudos nacionais com esses segmen- 
tos ${ }^{4}$. Entretanto, essenão pareceu ser o único critério de seleção dos alimentos no grupo. Assim, algumas mulheres fizeram referência à "marca" dos produtos: "[olho] o preço, o que é necessário e a marca", "o preço e a marca". Ana Maria Canesqui ${ }^{24}$ também observou, em seu estudo com as famílias trabalhadoras em São Paulo, um comportamento "consumista" por parte das mulheres na seleção dos gêneros alimentícios. De acordo com a autora, as mulheres demonstraram maior interesse em experimentar as "novidades", o que incluía a compra de novas marcas dos produtos. Contudo, em nossa investigação, constatamos que o preço de fato pareceu ser um fator determinante na aquisição dos alimentos no cotidiano de vida das mulheres do Vale: "eu procuro o que é mais necessário e mais barato, 0 que o dinheiro dá".

Em geral, a alimentação das mulheres era concebida como: "necessária", a "cesta básica", o "grosso". A alimentação cotidiana revelou ser monótona e incluía itens como o arroz, o feijão, a farinha, o óleo, o macarrão eo açúcar: "eu compro mais só o grosso: sal, arroz, farinha, feijão, óleo". Com menos frequência, apareceu na dieta das mulheres as frutas e as verduras: "verdura lá de vez em quando que a gente compra e eu sou hipertensa, mas eu como só o grosso mesmo, porque verdura é muito difícil, o dinheiro não dá, as despesas estão muito caras". A carne também foi citada com menor assiduidade pelo grupo: "uma carninha de vez em quando", "quando eu posso comprar carne, eu compro". O baixo consumo desses alimentos revelou a estreita relação entreas práticas alimentares e as condições materiais do grupo. Este regime se aproximou dealguns estudos realizados no país com mulheres das classes populares ${ }^{4,25}$.

Informações sobre preferências no consumo de alimentos revelaram o lugar privilegiado para as massas (macarrão), gorduras, as carnes em geral, especialmentea "carne de porco" e o "frango ao molho pardo". Entretanto, algumas entre vistadas revelaram a pouca margem para a seleção dealimentos, sintetizada no discurso de uma das mulheres: "aqui não tem preferência não, o que tiver se come, ninguém aqui recusa, não", "gostar eu gosto, mas não é sempre que pode comer". 0 uso do açúcar se mostrou frequente e diário no grupo, especialmente combinado ao suco e ao café: "só uso no suco", "eu só coloco açúcar no café". 0 gosto pelas preparações fritas também foi recorrente entre as mulheres, dentre elas: "batata frita", "mandioquinha frita" e "salgadinhos". Tais relatos denunciaram o conheci- mento das relações entrea ingestão de açúcares e de gorduras e a frequência da obesidade: "gostar eu gosto, mas eu evito", "[açúcar] uso e não posso, não posso porque estou com princípio de diabetes, mas eu não consigo controlar".

A predileção pelo açúcar e pelas gorduras tem sido comumente observada nos estudos com mulheres pobres eobesas no Brasil ${ }^{4,25}$. N estes trabalhos, evidencia-se a lógica da estratégia de consumo alimentar caracterizada na sel eção de gêneros al tamente calóricos e de baixo custo que promovem maior saciedade, mas não apenas isso. 0 aspecto cultural permeia a escolha ea sel eção desses gêneros no cotidiano de vida desses segmentos. Como afirma Fischler ${ }^{26}$, para serem comestíveis, os alimentos precisam ser elegíveis, preferidos, selecionados e preparados pela culinária, e tudo isso é regido por um componente cultural fundamental. N este sentido, a gastronomia brasileira rica ediversificada recebeu forte influência portuguesa, com a difusão dos açúcares, das gorduras e dos tubérculos ${ }^{27}$. Tais alimentos fazem parte da cultura e da identidade nacional.

A alimentação idealizada pelo grupo incluía a "carne", a "Iasanha", a "pizza”, a "torta", o "feijão tropeiro", o "arroz temperado", a "macarronada", concebida como uma "comida preparada", "comida especial". Interessante destacar que a "alimentação maissaudável" foi mencionadapor duas entrevistadas como uma alimentação de "Iuxo". E, dentre os alimentos de "luxo", apareceram as "frutas", cujo acesso é difícil frente à condição social do grupo: "eu gostaria de comprar mais frutas, mas elas são sempre mais caras", "frutas eu não compro, são muito caras e o dinheiro não dá". Limitações de ordem econômica na adesão a uma dieta mais saudável sob o ponto de vista nutricional, incluindo frutas e verduras, também foi verificada em outro estudo realizado com mulheres pobres e obesas ${ }^{4}$. Este fato revela as limitações no acesso aos principais meios de prevenção e combate à obesidade nas populações menos favorecidas economicamente.

A trajetória de vida das mulheres revel ou que as entrevistadas tiveram um passado sofrido, com o trabalho precoce, em geral, no roçado: "tinha que trabalhar na roça, capinar, plantar, fazer tudo! Minha vida era difícil demais!". De acordo com as mulheres, a alimentação nesta fase da vida era "boa" e "saudável". A experiência de prover e elaborar os alimentos tornava essa alimentação "melhor" quando comparada com 0 consumo de hoje, conforme mencionaram as entrevistadas: "ah, na infância a alimentação era melhor que agora, sem comparação! Porque a 
gente tinha leitinho tirado na hora. A alimentação era bem melhor do que agora", "a gente plantava, fazia farinha, fazia o café da manhã com garapa", "a gente não comprava nada não, era tudo plantado em casa, guardava os alimentos no paiol, né? Ensacados", "acho que a alimentação era melhor, não tinha química, tanta coisa quea gentecomehoje tem química, remédio, né? Era sadio, era uma coisa natural". Esse comportamento também foi verificado por Ferreira e $M$ agalhães ${ }^{4}$ com as mulheres pobres e obesas da Favela da Rocinha. Os produtos industrializados eram considerados alimentos "não naturais", já que se relacionavam ao uso de conservantese substâncias desconhecidas pelas mulheres, que também vivenciaram as experiências de plantare processar seus próprios alimentos na infância.

A rotina de atividades diárias das mulheres do Vale incluía os afazeres domésticos, o cuidado com os filhos, o trabalho informal e poucas horas de descanso e de lazer. De acordo com os relatos, "a vida é péssima pra todos, muito difícil", "o município, a administração deixa muito a desejar", "dizem que não esta ten do nem plantão mais! Não tem um médico!", "falta emprego para as pessoas", "não tem opção de lazer, a cidade está imunda, está suja, rato pra todo o canto, porque não tem prefeito pra mandar recolher 0 lixo. Então aqui tá uma vergonha!", "olha o lugar quea gente mora? É pior que uma favela. Ondeé mais caprichadinho é só no centro".

Dentre as facilidades de se morar na cidade de Diamantina, as mulheres citaram a tranquilidade e a segurança: "é mais tranquilo, aqui tem pouca violência", "é uma cidade calma", "sossegada". Em seu cotidiano diário, as entrevistadas tentavam conciliar os afazeres domésticos com a jornada de trabalho informal: "eu acordo cinco e meia, limpo casa, arrumo cozinha, lavo roupa, costumo dar banho nas meninas pra poder ir pra escola. Aí seteemeia vou para o trabalho. Eu chego faço café, arrumo a casa, depois vou fazer almoço, lavar roupa, banheiro. Aí cinco e meia, volto pra casa". D o total de entrevistadas, apenas três mencionaram realizar atividade física de lazer diariamente: "eu acordo 6 e 15, caminho até 15 pras 8, tomo banho evou trabal har", "eu acordo cedo, tomo remédio e faço a caminhada, chego da caminhada e vou cuidar das nossas coisas dentro de casa". As horas de descanso e lazer demonstraram ser raras. Assistir televisão, por exemplo, somenteno período da noite, por poucas horas, devido à falta de tempo. A esse respeito, estudos nacionais ${ }^{28,29}$ têm constatado maiores prevalências de sedentarismo entre 0 grupo feminino quando comparado ao masculino. Dentre as justificativas para a inatividade física no grupo feminino, emergiu a questão das múltiplas jornadas de trabalho, acarretando um menor tempo para o lazer. De fato, de acordo com o IPEA ${ }^{19}$, as mulheres realizam em média mais horas semanais com os afazeres domésti$\cos (24,8$ horas) do que os homens ( 10,0 horas).

\section{Alimentação e corpo}

Diferenças nos regimes alimentares das crianças e dos adultos foram observadas. As muIheres relataram que, para as crianças, as variações do cardápio envolvem a adição de "frutas" e "verduras": "eu faço uma comida assim, procuro fazer com mais verdura, coisas assim pra elas, porque mesmo se não tiver pra gente, pra criança tem que ter". De acordo com as mulheres, as variações na alimentação ocorrem "porque para a criança, tem que fazer uma coisa mais diferente pra ela desenvolver. Às vezes, tem que dar uma sopa, fazer uma carnemais preparada, não éigual adulto", "existe [diferença] porque nem tudo que a gente pode comer pode dar para uma criança", "a [alimentação] da criança tem que ser mais suave, mais levinha, né?"

Contudo, embora reconheçam as necessidades e demandas al imentares das crianças no cotidiano diário, essas modificações do cardápio nem sempre podem ser realizadas: "não existe diferença, não", "o que um comer, os outros comem", "é tudo igual porque às vezes não tem uma fruta, não tem iogurte". Entretanto, verificamos que a pouca margem de escolha faz com que algumas mulheres abdiquem de al imentos mais saudáveis enutritivos em favor dos filhos: "a criança é mais sensível, ela tem que ter uma alimentação mais equilibrada. É diferente, por exemplo, se tem um leite, eu tenho quedeixar mais pra criança do que pra mim. Fruta eu tenho quedeixar mais pra elas, porque elas estão em desenvolvimento. Eu posso esperar". Esse comportamento também foi verificado por Aguirré $\mathrm{e}^{30} \mathrm{em}$ seu estudo com as muIheres obesas e de baixa renda na Argentina.

Diferenças acerca da alimentação entrepobres e ricos foram evidenciadas. Assim, para as muIheres, a comida de rico é "bem diferente", "variada", "chique", "incrementada" e, portanto, "meIhor". A comida de rico permite, de acordo com as entrevistadas, a inclusão de gêneros caros, itens cujo acesso é difícil, tais como a "carne", a "salada", a "verdura" e as "sobremesas": "muitas vezes o pobrenão pode ter a carne, já o rico pode. Uma salada e o rico pode", "rico tem uma verdura, 
uma salada. Comida de pobre, às vezes você faz arroz, feijão, macarrão, angu, só", "rico comebem, pobre come mal", "na maioria das vezes, eles comem muita salada". A comida de rico também é concebida pelas mulheres como sendo "leve", "sem gordura": eles [ricos] comem pouco pra não engordar, tudo tem que ser assim, tipo assim, sem gordura, leve". Em contrapartida, o pobre come "o básico", "o que dá pra comprar". No dia a dia, a alimentação se revela monótona, composta por: "arroz com feijão", "às vezes, verdura não tem", "come a carne quando tem" e "muita massa", " a gente come muita comida pesada".

Com relação ao corpo, a maior parte das mulheres revel ou estar insatisfeita com o seu peso. Ter excesso de peso para o grupo significava: "sentir-se mal", "não ter boa saúde", "ficar estressada", "anêmica", "com glicose alterada", "colesterol alto", "sedentária", "ter mais tendência a enfartar e a ter hipertensão". Além disso, o corpo obeso dificultava o vestuário ea aceitação social: "éruim, os outros vivem chamando a gente de gorda", "é até mais difícil pra comprar roupa, esteticamente, também, é um pouquinho difícil". Para as mulheres, a obesidadeacarreta limitaçõesimportantes no cotidiano de vida, que compreendia comprar um vestuário confortável, realizar sua rotina de atividades diárias e do trabalho, manter-sesaudável: "a gentevesteuma roupa ea gente não se sentebem, não se sentealegre, não se sente confortável", "tem coisa que eu não consigo fazer: correr, andar rápido, eu fico cansada", "dificuldade pra trabalhar", "a autoestima da gente fica baixa”, "cansaço", "falta dear", "estresse”, "traz muito problema, doença".

Tais discursos nos conduzem a pensar em mudanças nas representações sociais relacionadas ao corpo, à saúde e à doença operando nesse grupo, em particular. Em geral, os estudos que investigaram essas temáticas ao longo da década de oitenta no Brasil referiam-se à importância da categoria "força/fraqueza" pelas classes populares. Dessa maneira, o corpo "forte" era vinculado à "saúde" e ao "trabalho" 31,32. O postamente, a doença relacionava-se à fraqueza, ao desânimo, ao corpo desnutrido, à magreza, à escassez e à fome. Notadamente, observamos que 0 corpo obeso para as mulheres do Vale era percebido pelas sensações de indisposição para trabaIhar e realizar as atividades cotidianas do grupo e, dessa forma, era concebido como um "corpo fraco". Ao mesmo tempo, observa-se também a incorporação do discurso médico regido por preceitos normativos (dieta, exercício físico, emagrecimento, cuidados estéticos, exames periódi- cos, etc.), mais comumenteverificado nas classes média/alta e nos indivíduos com melhor nível intelectual ${ }^{33}$.

A gravidez foi sinalizada pelas mulheres como a principal justificativa para o ganho depeso. D essa forma, de acordo com as entrevistadas: "comecei a ganhar peso depois queeu tiveo primeiro filho", "depois da gravidez", "na minha terceira gestação", "a gente tem filho ealarga a barriga", "depois que eu ganhei a menina". Estudos nacionais têm demonstrado a relação positiva entre gravidez e excesso de peso em mulheres ${ }^{34}$. 0 uso de fármacos também foi relacionado ao ganho de peso no grupo: "foi por causa do medicamento antialérgico", "remédio de estômago", "vitamina pra engordar que eu tomei na adolescência".

\section{Desigualdades \\ no acesso ao estilo de vida saudável}

A maior parte das mulheres revelou aderir a al gum tratamento para emagrecer: "já fiz detudo que você possa imaginar". Dentre os recursos mais citados, estavam caminhada, dieta, exercício eremédio. No quediz respeito à dieta, a maior parte das mulheres revelou já ter se consultado com médicos, nutricionistas e estagiárias de nutrição que estão nos serviços de saúde locais. Com relação ao tratamento dietoterápico, as mulheres revelaram que foi bom; contudo, não deram continuidade: "foi um tratamento até bom, mas eu que não continuei", "no início, eu perdi, aí depois eu comecei a ganhar peso, aí eu fui e deixei". De acordo com o grupo, o tratamento dietético "foi muito importante pra saúde", "importante, mas eu não consegui dar sequência". Estudo realizado por Cavalcanti et al..$^{35}$ revelou que o grupo de obesos de baixa renda associava a perda de peso (regime) a crenças positivas tais como "sentir-se leve", "mais disposto", "ter mais saúde", "evitar doenças", "meIhorar a autoestima".

Investigando as dificuldades para perder peso no grupo, verificamos a culpabilização das muIheres pelo seu corpo obeso: "é falta de força de vontade mesmo", "eu como muita comida pesada", "se eu tivesse mais atividadefísica", " acho que éporqueeu como muita massa”, "podiafazer mais um pouquinho deatividade física", "eu fico muito parada". Entretanto, as categorias "nervoso" e"estresse" apareceram com muita recorrência no discurso das mulheres: "eu sou meio desesperada, às vezes fico querendo ter as coisas, vejo os meninos pedindo, fico estressada", "é ansiedade", " é mais por causa do nervoso, se a gentetivesse uma vida 
mais tranquila”, "eu acho que eu sou gorda nem é de comer tanto, é mais estresse".

De acordo com o grupo, para perder peso, seriam necessárias as seguintes medidas: 0 acompanhamento com o "médico" ou com a "nutricionista", fazer "dieta" e "caminhadas". Contudo, pouco a pouco, revelaram as reais limitações para a adesão ao tratamento: "vou ter que procurar um médico, né? Que a gente não encontra, porque a gente vai no posto, vai na secretaria e não encontra um médico pra gente consultar", "Diamantina éassim: tudo éacademia, tudo que você precisa é caro, não tem um centro assim, deveria existir um centro assim pra gente, até pra caminhada é difícil, porque podia fazer um local, a gente anda, faz caminhada, preocupada com 0 carro que vai te pegar, não tem uma área assim pra você fazer uma caminhada", "poderiam ajudar as pessoas que não têm condição de pagar uma academia, deveria existir al guma coisa assim de graça", "a gente deveria se alimentar pouco, comer mais verdura, fruta, né? Evitar muita comida pesada de feijão-arroz, feijão-arroz", "se a gente tivesse mais condições de fazer uma dieta certa, mais tranquilidade na vida", " se eu tivesse uma condição melhor, poderia fazer dieta", "eu acho que se a gente tivesse condições de comer outras coisas, verduras, por exem plo, quem sabe?".

\section{Considerações finais}

Este trabalho corrobora os estudos nacionais e internacionais mais recentes que alertam para a complexidade da dinâmica da obesidade feminina na pobreza $3,4,24,36,37$. As mulheres, chefes de família ou não, que recebem baixos rendimentos, possuem menor nível deinstrução, não apresentam seguridade e proteção social, são extre mamente vulneráveis à obesidade e suas comorbidades $^{38}$. Concomitantemente, essas mulheres dispõem depoucos recursos para aderir aos prin- cipais instrumentos de prevenção e combate à obesidade ${ }^{36}$. Neste sentido, cabe salientar a importância de fomentar políticas públicas de inserção social eigualdadede gêneros, além de ações focalizadas na promoção a estilos de vida saudáveis. Estas últimas devem propiciar espaços recreativos e delazer para a prática regular deatividade física nos circuitos da pobreza (quadras esportivas, ciclovias, pistas para caminhadas, etc.), além da difusão de orientações para a prática esportiva nos diferentes cenários (escolas, trabalho, associações de bairros, unidades básicas de saúde, meios de comunicação de massa).

Soma-se a estas ações a ampliação da garantia do acesso a alimentos mais nutritivos e de menor densidade calórica, tais como as frutas e verduras, dentro da perspectiva da segurança alimentar e nutricional. A segurança alimentar e nutricional preconiza ações múltiplas queenvolvem a redução do preço desses alimentos: 0 incentivo à criação de hortas comunitárias e da agricultura urbana e de subsistência; a restrição de campanhas de marketing a alimentos ricos em açúcares e gorduras; a divulgação de guias alimentares e de campanhas educativas nos meios de comunicação de massa que fomentem 0 consumo de alimentos de melhor qualidade nutricional; o incentivo ao consumo de alimentos regionais, dentre outras iniciativas.

Por fim, destacamos a importância de incorporar os aspectos simbólicos, culturais e materiais de vida para a análise das múltiplas faces da enfermidadeno Brasil ${ }^{4}$. Os exames quepropõem a articulação das dimensões do corpo, do trabaIho, da cultura, da condição de classe e saúde devem ser incorporados aos estudos atuais acerca do tema, a fim de possibilitar o melhor enfrentamento do agravo. A nosso ver, o delineamento ea execução de pesquisas eações focal izadas são imprescindíveis para a redução do impacto potencialmente negativo da obesidadenestes segmentos hoje no país. 


\section{Colaboradores}

VA Ferreira foi responsável pela idealização, orientação da pesquisa eredação do artigo. AE Silva realizou a transcrição das entrevistas e a revisão do artigo. CAA Rodrigues foi responsável pela seleção da amostra, coleta de dados e revisão do artigo. N LA Nunes participou da seleção da amostra, da coleta de dados e revisão do artigo. TC Vigato foi responsável pela coleta de dados ere visão do artigo.

\section{Agradecimentos}

À Fundação de Amparo à Pesquisa do Estado de Minas Gerais (FAPEMIG) pelo apoio financeiro.

\section{Referências}

1. Força Tarefa Internacional sobre O besidade. [site da Internet] [acessado 2008 mar 02]. Disponível em: http://www.iotf.org

2. Pena M, Bacallao J. La obesidad en la pobreza: un nuevo reto para la salud pública. Washington, D.C.: OPAS; 2000.

3. Instituto Brasileiro de Geografia e Estatística. Pesquisa de orçamentos familiares 2002-2003: análise da disponibilidade domiciliar de alimentos e do estado nutricional no Brasil. Rio de Janeiro: IBGE; 2004.

4. Ferreira VA, Magalhães R. Obesidade e pobreza: 0 aparente paradoxo. Um estudo com mulheres da Favela da Rocinha, Rio de Janeiro, Brasil. Cad Saude Publica 2005; 21(Supl. 6):1792-1800.

5. Brasil. Ministério da Saúde. Secretaria de Atenção à Saúde. Departamento de Atenção Básica. O besidade. Brasília: Ministério da Saúde; 2006.

6. Coutinho JG, Gentil PC, Toral N. A desnutrição e obesidade no Brasil: o enfrentamento com base na agenda única da nutrição. Cad Saude Publica 2008; 24(Supl. 2):332-340.

7. Helman CG. Cultura, saúde e doença. Porto Alegre: Artmed; 2003.

8. Instituto Brasileiro de Geografia e Estatística. Pesquisa Nacional de Amostra Domiciliar. Rio de Janeiro: IBGE; 2007.

9. Geografia de Diamantina. [site da Internet]. [acessado 2008 mar 02]. Disponível em: htpp//:www. diamantina.mg.gov.br

10. Silveira FG, Carvalho AXY, Azzoni CR, Campolina $B$, Ibarra A. Dimensão, magnitude e localização das populações pobres no Brasil. Brasília: IPEA; 2007. [Texto para discussão ํo 1.278].

11. Secretaria M unicipal de Saúde de Diamantina. Sistema de vigilância alimentar e nutricional: 2002-2007. [Mimeo]

12. Batista Filho M, Rissin A. A transição nutricional no Brasil: tendências regionais e temporais. Cad Saude Publica 2003; 19(Supl. 1):181-191.

13. M inayo MCS. Pesquisa social: teoria, método e criatividade. Petrópolis: Vozes; 1998.

14. World Health Organization. O besity: preventing and managing the global epidemic. Report of WHO Consultation on Obesity. Geneva: World Health Organization; 1997.

15. Sen AK. Desigualdade reexaminada. Rio de Janeiro: Record; 2001.

16. Townsend P. The international analysis of poverty. London: Harvester Wheatsheaf; 1993.

17. Rocha S. Caracterização da pobreza no Brasil. In: IPEA. O Brasil no fim do século: desafios e propostas para ação governamental. Rio de Janeiro. IPEA; 1994. p. 37-43.

18. Fundação João Pinheiro. Perfil de M inas Gerais, 2007. Belo Horizonte: FJP; 2008.

19. Instituto de Pesquisa Econômica e Aplicada. Retrato das desigualdades de gênero e raça. Análise preliminar dos dados. Brasília, IPEA; 2008.

20. Sarlio-Lähteenkorva S, Lahelma E. The association of body mass index with social economic disadvantage in women and men. Int J Epidemiol. 1999; 28(3):445-449. 
21. Núcleo de Estudos de Políticas Públicas. Família e pobreza. Relatório final. Campinas: Universidade Estadual de Campinas; 1992.

22. Woortmann K. A família das mulheres. Rio de Janeiro: Tempo Brasileiro; Brasília: Conselho de Desenvolvimento Científico e Tecnológico; 1987.

23. Federação de Comércio do Estado do Rio de Janeiro. Jornal 0 Globo 2008; 30 mar.

24. Canesqui AM. Mudanças e permanências da prática alimentar cotidiana de famílias de trabalhadores. In: Canesqui AM, organizadora. Antropologia e nutrição: um diálogo possível. Rio de Janeiro: Fiocruz; 2005. p.167:210.

25. Tonial SR. Desnutrição e obesidade: faces contraditórias na miséria e na abundância. Recife: IM IP; 2001.

26. Fichler $\mathrm{Cl}$. (H) omnivore. Paris: Odile Jacob; 1990.

27. Zarvos N, Ditadi CAS. Multissabores: a formação da gastronomia brasileira. São Paulo: Senac; 2001.

28. Instituto Nacional do Câncer. Inquérito domiciliar sobre comportamentos de risco e morbidade referida de doenças e agravos não transmissíveis. Rio de Janeiro: Inca; 2004.

29. Salles-Costa R, Heilborn ML, Werneck GL, Faerstein $E$, Lopes CS. Gênero e prática de atividade física de lazer. Cad Saude Publica 2003; 19(Supl. 2):325-333.

30. Aguirre P. Aspectos socioantropologicos de la obesidad en la pobreza. In: Pena M, Bacallo J, compiladores. La obesidad en la pobreza: un nuevo reto para la salud publica. Washington, D.C.: OPAS; 2000. p.13-25. [ Publicación científica $n^{\circ}$ 576]

31. Duarte LFD. Da vida nervosa nas classes trabalhadoras. Rio de Janeiro: Jorge Zahar/ Cnpq; 1986.

32. Zaluar A. Os trabalhadores e suas famílias: trabaIho e pobreza. In: Zaluar A. A máquina e a revolta: as organizações populares e o significado da pobreza. São Paulo: Brasiliense; 1984. p 87-131.

33. Bolstanki L. As classes sociais e o corpo. Rio de Janeiro: Graal; 1984

34. Kac G. Fatores determinantes da retenção de peso no pós-parto: uma revisão da literatura. Cad Saude Publica 2001; 17:455-466.

35. Cavalcanti APR, Dias M R, Rodrigues CFF, Gouveia CNNA, Ramos DD, Serrano FJO. Crenças e influências sobre dietas de emagrecimento entre obesos de baixa renda. Cien Saude Colet 2007; 12(Supl. 6):1567-1574.

36. Wardle J, Waller J, Jarvis MJ. Sex differences in the association of socioeconomic status with obesity. Am J Public Health 2002; 92(8):1299-1304.

37. Wardle J, Griffith J. Socioeconomic status and weight control practices in British adults. J Epidemiol Community Health 2001; 55(3):185-190.

38. Dijkshoorn H, Nierkens V, Nicolaou M. Risk groups for overweight and obesity among Turkish and Moroccan migrants in The Netherlands. Public H ealth 2008; 122:625-630.

Artigo apresentado em 26/06/2007

Aprovado em 14/12/2007

Versão final apresentada em 04/04/2008 